\title{
Simulation and Measurement of Through-the-earth (TTE), Extremely Low- Frequency Signals using Copper-clad, Steel Ground Rods
}

\author{
Nicholas Damiano, Lincan Yan, Bruce Whisner, and Chenming Zhou \\ National Institute for Occupational Safety and Health \\ Pittsburgh Mining Research Division \\ 626 Cochrans Mill Road \\ Pittsburgh, PA 15236, USA \\ NDamiano@cdc.gov, LYan1@cdc.gov, BWhinser@cdc.gov, CZhou@cdc.gov
}

\begin{abstract}
The underground mining environment can greatly affect radio signal propagation. Understanding how the earth affects signal propagation is a key to evaluating communications systems used during a mine emergency. One type of communication system is through the earth (TTE) that can utilize extremely low frequencies (ELF). This paper presents the simulation and measurement results of recent National Institute for Occupational Safety and Health (NIOSH) research aimed at investigating current injection at ELF, and in particular ground contact impedance. Measurements were taken at a surface testing location, outside. The results obtained from modeling and measurement are characterized by electrode impedance and the voltage received between two distant electrodes. The paper concludes with a discussion of design considerations found to affect low-frequency communication systems utilizing ground rods to inject a current into the earth.
\end{abstract}

Index Terms-low-frequency communications, grounding, ground rods.

\section{INTRODUCTION}

The Mine Improvement and New Emergency Response Act of 2006 (MINER Act) [1] mandated that every underground coal mine in the U.S. develop an emergency response plan within three years that includes two-way, postaccident, wireless communication and tracking. This plan must provide for communications between underground and surface personnel, and electronic tracking of all underground mine workers. A survey completed in 2014 showed that all active underground coal mines have installed a system that operates in the very high-frequency or ultra high-frequency bands [2].

Communication between personnel on the surface and miners underground is especially important during emergencies such as methane or coal dust explosions, belt fires, or entrapments from a large ground fall or pillar burst. In such circumstances, very high-frequency or ultra highfrequency band communication systems might be interrupted because their infrastructure may be damaged. Communication signals are subsequently blocked by the surrounding earth, attenuate on existing conductors once they have been damaged, or power is lost to critical parts of the system that prevents those signals from reaching the surface. One of the major benefits of extremely low-frequency (ELF) signals is that they can travel directly through the earth without the need for special infrastructure that may susceptible to the type of damage experienced after a disaster unfolds.

In a situation where escape to the surface is cut off, trapped underground coal miners may enter a refuge alternative (RA). This RA has provisions for communications, lighting, sanitation, food, water, and first aid. The final rule for RAs also states "Communications with the persons in refuge alternatives are vital to mine rescue efforts. The knowledge of where miners are in refuge alternatives, their condition, and the conditions in the mine may make the difference between life-and-death in a post-accident crisis." [3]. The RA typically achieves communication through a wired connection or the presence of a post-accident wireless communication system. However, it can be envisioned that since an RA is designated as the last option, it is possible that this connection may be broken. The mine's communication system infrastructure can be susceptible to catastrophic damage caused by the previously mentioned events. Systems that do not utilize a large amount of infrastructure may be more likely to remain operational after a large accident.

ELF communications typically involves grounding to the earth using the lowest resistance path possible and injecting a current higher than 1 amp. The ELF signals conduct through earth where they can be received by another ELF radio kilometers away. ELF systems can utilize a variety of different means to connect to ground including power system ground beds, metal cased boreholes, rails, and any metallic support structure connected to earth [4].

There is currently one system which is designed to directly connect to earth. This system is classified as a through-theearth (TTE) system [5]. The system uses roof bolts to connect to the earth underground which is similar, in principle, to Fig. 1. There exist two other systems that are classified as TTE systems but do not operate in the ELF band-rather, they operate slightly above that in the very low-, ultra low-, and super low-frequency bands. These systems may also be able to utilize ground rods that directly connect to earth.

\section{EXTREMELY LOW-FREQUENCY COMMUNICATIONS}

ELF covers a part of the electromagnetic spectrum from 3 to $30 \mathrm{~Hz}$. This band is mainly used for submarine 


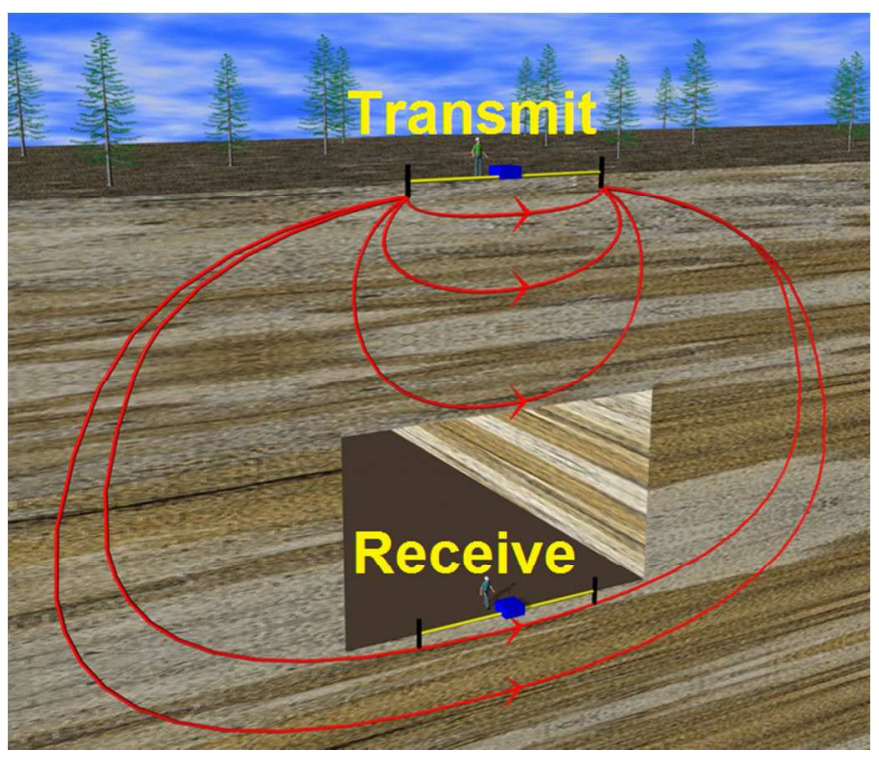

Fig. 1. A drawing of an ELF transmission between surface and underground.

communication around the world. The permissible ELF system has low bandwidth and currently only supports a single channel for canned messages. Canned messages are messages where a single transmitted symbol represents a common word or group of words. Those symbols can then be used to transmit a common message such as "help me." These limitations may make any permissible ELF system only useful during an emergency when all other means of communications have failed. An ELF system could provide an alternate path for communication from the underground to the surface that would possibly remain intact after a disaster. This system could be placed nearby a RA or other strategic location underground where miners are trapped.

On the surface, ELF systems can operate with very long antennas and utilize high-power transmissions. The very long antennas are capable of radiating power in the ELF system. Underground, however, the power used by these radios have to meet permissible requirements for U.S. underground coal mines, and extremely long antennas are not practical. Nonetheless, it has been observed that, by injecting a current directly into the ground ELF signals can travel over $1 \mathrm{~km}$ provided the earth contact impedance and signal attenuation do not inhibit the system's transmit signal. For ELF systems, the impedance the transceiver acquires once connected to ground plays a significant role in the performance of this system.

A basic ELF communication system consists of one ELF transceiver connected to two earth electrodes separated by a distance. In order to produce an ELF signal in earth, a potential difference must be generated between two earth electrodes. These electrodes may consist of several ground rods, some combination of grounded metal structure, or single rods in the simplest case. Current passing through the electrodes can generate a current in the earth. This current then propagates through the earth medium for some distance
[6]. Another set of electrodes a distance away can detect the transmitted signal as a potential difference using the same principle of two electrodes. How far this current can travel through earth depends on factors such as, but not limited to, earth conductivity (multilayer), the contact impedance of each electrode, and transmitted current.

Earth conductivity $(\sigma)$ is expressed in Siemens per meter. Due to variations within the earth, this value may change over distance. A multilayer model is more representative of the earth but it is challenging to predict. Earth can have many different layers such as clay, sandstone, and shale that vary in the moisture content, salt concentration, and soil temperature that affects resistivity [7]. Also, these layers have boundary zones where transitions between layers may or may not be abrupt. Further, the surface of the earth provides a complex layer in which factors such as vegetation and terrain affect the makeup.

For earth contact impedance, one must consider the effects of connecting an electrode to lossy earth; earth is not a perfect conductor. There is an impedance associated with connecting an electrode to ground. Therefore, the conductivity used in simulation models was based on previous experimental findings. For conducting earth materials where the ratio of $\sigma$ and the relative permittivity times the angular frequency $(\varepsilon \omega)$ is much greater than 1 , this impedance is almost entirely real for these frequencies, and can be approximated with algebraic expressions [8-9]. Ultimately, it is not possible to obtain a complete short at an electrode. The best that can be achieved is an approximation of a short to ground by providing $\mathrm{Zr}<<\mathrm{Z}_{0}$, where $\mathrm{Zr}$ is the contact impedance between the electrode and earth and $Z_{0}$ is the characteristic impedance of the transmitter.

The transmitted signal has some attenuation rate and as long as the transmitted signal is large enough to overcome the attenuation rate, it can be seen by the receiver a distance away. For example, if the real part of the contact impedance is low $(1 \mathrm{ohm})$ and the conductivity of earth is high ( 0.03 $\mathrm{S} / \mathrm{m})$ then the required current may not be very high $(1 \mathrm{amp})$ to generate a signal that may be detected several kilometers through the earth.

\section{ANALYTICAL MOdel OF GROUND IMPEDANCE}

For calculating the impedance of a ground rod in earth (Zr), several models exist [10]. For this analysis, consider the following simplified contact electrode impedance formula taking into account 4 variables:

$$
\mathrm{Zr}=\frac{1}{4 \pi \sigma l} \ln \left[\left(\frac{4 l}{a}\right)-1+\frac{1}{d}\right]
$$




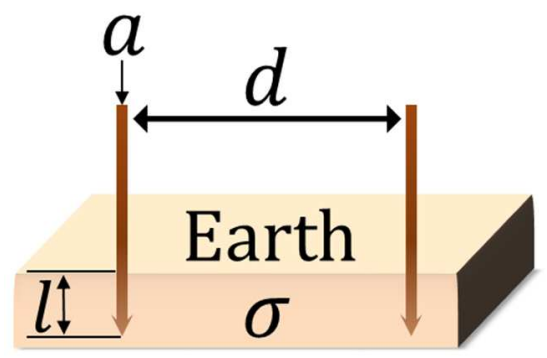

Fig. 2. A drawing of an analytical model of two electrodes in earth medium.

where:

$\sigma$ is the earth's conductivity $(\mathrm{S} / \mathrm{m})$

$l$ is the depth of the rods in earth

$a$ is the rod radius

$d$ is the separation distance between two vertical rods

This formula does not take into account the frequency of the signal. It assumes a single rod for each electrode. It also does not take into account possible inductance and capacitance of the system, including the ground rod connection between earth and itself, which may have a complex component to its impedance [11]. For several other models, consideration has been given to complex values of the impedance. Variables used in this formula are depicted in Fig.2.

\section{Numerical SimUlation with FEKO}

FEKO is an electromagnetic simulation software tool for the analysis of three-dimensional structures. FEKO utilizes multiple numerical methods for the solution of Maxwell's equations to solve electromagnetic problems. In this study, this software was used to simulate values of the impedance of the electrodes for comparison to field measurements.

ELF electrodes and transmitter were created (Fig. 3) using FEKO to simulate various representative scenarios. These scenarios constitute a few simple considerations (ex. depth and number of ground rods) in designing ELF electrodes that could be used to communicate through earth.

When comparing simulation results to measurement expectations of an ELF system, there are several factors to

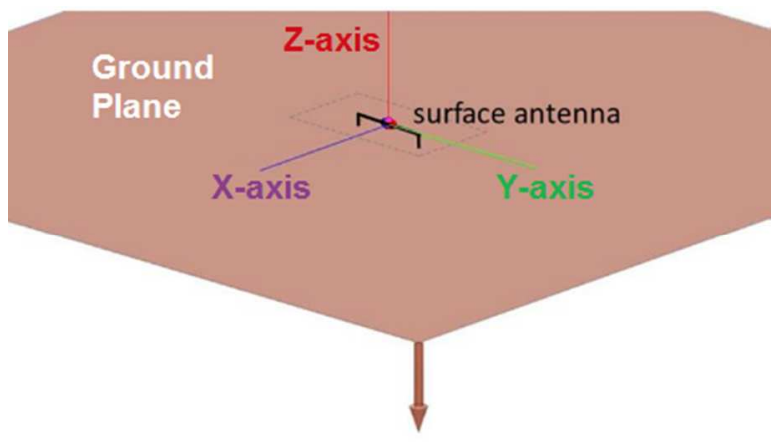

Fig. 3. FEKO simulation using single-rod electrodes.

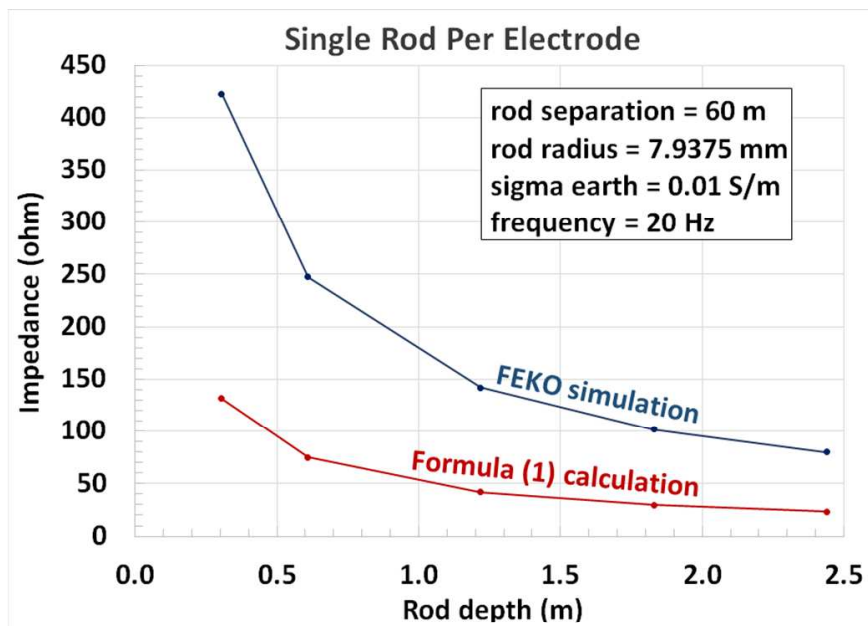

Fig. 4. Simulation and analytical results of a single-rod electrode in earth. consider. Simulation will allow for imperfect connectors, separation distances, and different transmit and receive electrodes, but were not considered in this simulation. Certain factors such as terrain of the earth may affect alignment in three-dimensional space; however, for the simulation this was also not considered.

To begin to look at system impedance, a simple scenario of a single ground rod for two electrodes separated by $60 \mathrm{~m}$ was simulated. The two rods had a radius of about $7.9 \mathrm{~mm}$ each and the frequency was $20 \mathrm{~Hz}$. In Fig. 4, analytical results were compared although there was no consideration for frequency in the formula. Models were plotted as a function of rod depth. Impedance for both models follow a decaying exponential. It would appear that the two curves may converge but at depths exceeding $2.5 \mathrm{~m}$.

\section{ImPEDANCE MEASUREMENT System AND SetuP}

The measurement system consisted of 12-volt batteries, an audio amplifier, a calibrated passive current probe (model BCP-510 passive current probe from AH systems, Inc.), a voltage divider for measuring voltage, and a controller to collect data (Fig. 5). This system was controlled using a computer and the data collected was stored on it. Two identical systems were assembled so that signals could be transmitted and received by relatively identical setups. Measurements were taken sequentially over the period of a

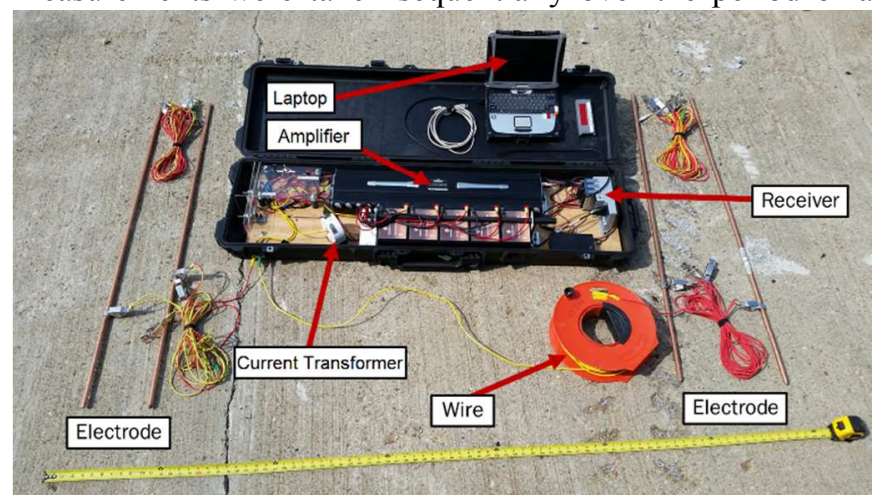

Fig. 5. Electrode based TTE measurement system. 


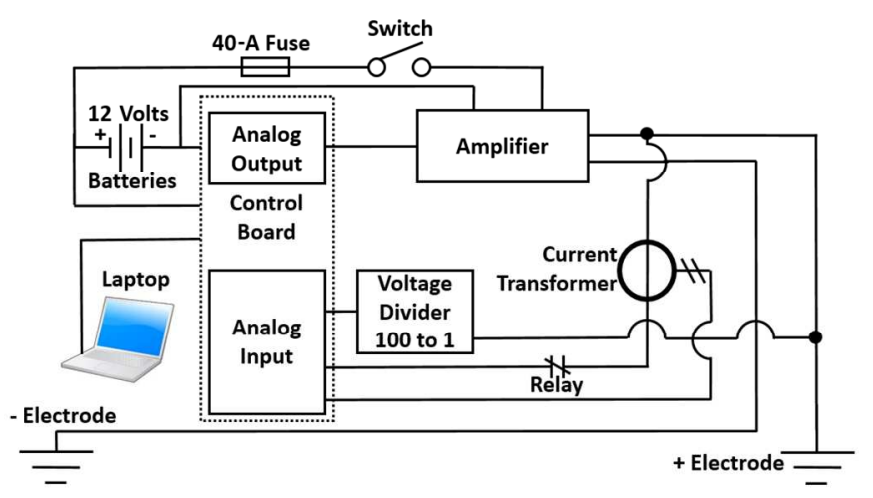

Fig. 6. Block diagram of the TTE measurement system.

few weeks.

For the connection to ground, 1.58-cm diameter copperclad steel ground rods were chosen for each electrode. These rods are standard for connecting residential power system grounds in the U.S. Ground rods were connected using 60amp charging clamps. Each clamp was crimped to a group of conductors consisting of insulated 10-gauge copper stranded wire to a central point. The central points of each electrode were connected to the amplifier's negative and positive outputs using a 60 -m-long conductor of the same gauge wire. A block diagram is shown in Fig. 6 .

The control board consisted of analog output consisting of a continuous sine wave using a 24-bit National Instruments analog output module model NI 9269. The signal being transmitted was monitored using an analog input (model NI 9239) connected to a current transformer. When current was not being transmitted, voltage read directly from the electrodes.

Measurements were taken in a surface test area (Fig. 7) that had no others conductors within $100 \mathrm{~m}$ of the electrodes. The test area had gently rolling hills over much of the $365 \mathrm{~m}$ used for the experiment. The overall earth was slightly compact and dry to the touch for the testing areas. Vegetation consisted of tall grasses with trees throughout.

Experiments were conducted in three separate tests (Fig. 8):

1) The ground contact impedance based on the number of ground rods per electrode.

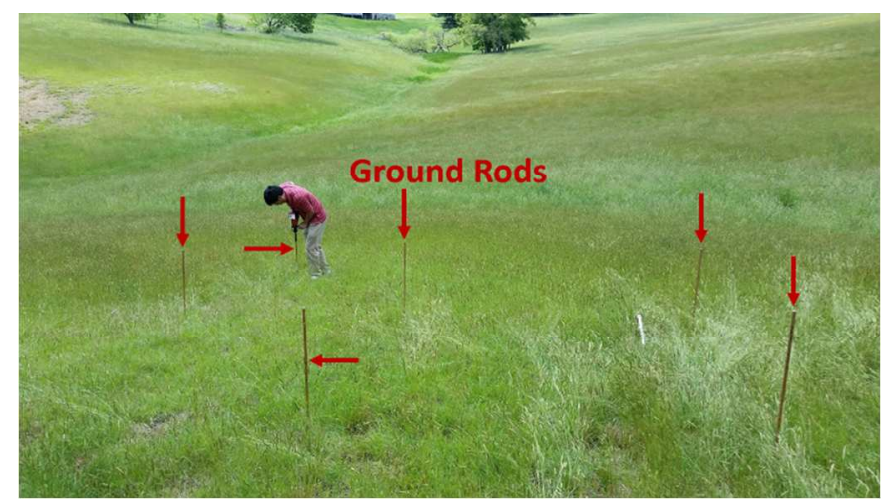

Fig. 7. Installing rods in a single earth electrode location.

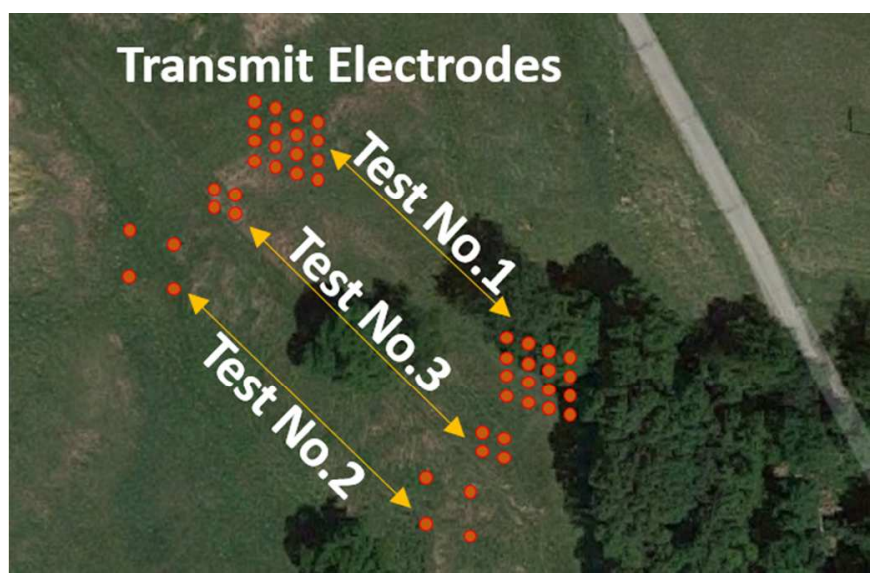

Fig. 8. A satellite image of the transmit area. The orange dots indicate a single ground rod's location. A cluster of dots represents one electrode.

2) The ground contact impedance based on the depth of ground rods.

3) The ground contact impedance based on the method of installation of the ground rods.

Test no. 1 consisted of varying the number of ground rods with fixed depth in each transmit electrode. Subsequent ground rods were driven into the earth separated in all directions by at least two times the rod depth, or $2.4 \mathrm{~m}$ each, in a square or rectangular pattern in order to reduce the influence caused by an adjacent rod [12].

Test no. 2 consisted of varying the depth of each ground rod with a fixed number of rods. Test no. 2 utilized only four ground rods, $4.8 \mathrm{~m}$ apart for each electrode. Ground rods were $2.4 \mathrm{~m}$ long and were all driven into the ground to the same depth at the same time. All transmit rods for test no. 2 began at $0.3 \mathrm{~m}$ deep and were incrementally driven another $0.3 \mathrm{~m}$ until they were $2.4 \mathrm{~m}$ deep. Measurements were taken at each increment.

Test no. 3 consisted of using 4 of the 16 rods from test no. 1 to compare to four newly installed rods of exactly the same length. Instead of directly driving these new ground rods into the earth as in all previous tests, these rods were installed by drilling into the earth first and removing any loose earth, leaving a 1.5-cm-diameter hole in the ground. A hammer drill and 1-m-long drill bit were used to make the hole. Once the hole was completely drilled out, a mixture of water and copper (II) sulfate, or $\mathrm{CuSO}_{4}$ solution. $\mathrm{CuSO}_{4}$ is used in Geophysical exploration to improve ground contact. $\mathrm{CuSO}_{4}$ solution was poured into the hole several times until it was completely saturated with solution (solution level remained visible near the surface for at least 15 minutes). Ground rods were then inserted into the holes saturated with solution and driven another $0.2 \mathrm{~m}$. The rods were left alone for at least 24 hours before testing began. All rods were driven into the ground and for all tests the rods were unable to be removed by hand, thus ensuring that some earth held on at least part of the rod. In the case of the rods treated with the $\mathrm{CuSO}_{4}$ solution, all of them were still wet with solution 24 hours later when testing commenced. 


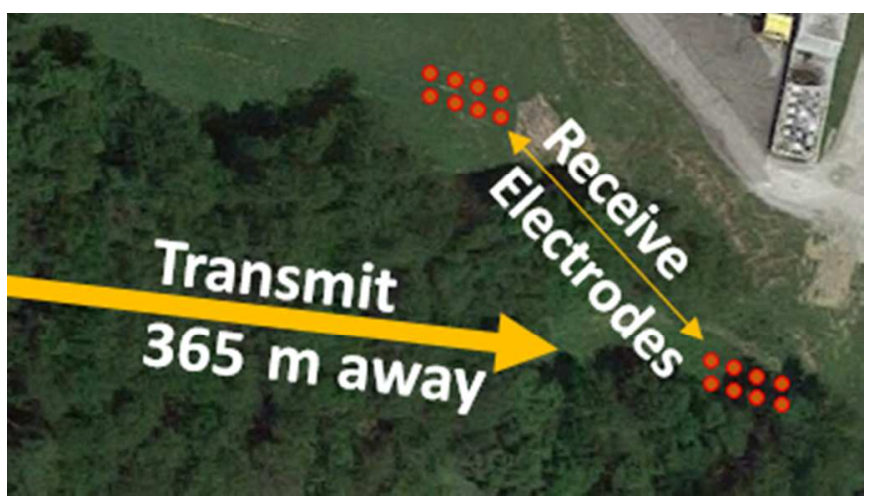

Fig. 9. A satellite image of the receive area. The orange dots indicate a single ground rod's location. A cluster of dots represents one electrode.

Each test was conducted in coordination with a similar measurement system $365 \mathrm{~m}$ away (Fig. 9). This receive location consisted of the same hardware and setup except its electrodes were fixed in design for all tests. The receive location had two electrodes consisting of eight 1.2-m-long ground rods directly driven all the way into earth. Electrodes for the receive system were installed in rectangular formation and separated by $60 \mathrm{~m}$. The AC voltage potential produced by the transmitter was measured at known intervals and recorded. Coordination between the transmitter and receiver systems was accomplished using handheld high-frequency radios. Both the transmitter and receiver systems were synchronized to record voltage and current at the same time.

\section{Simulation and Measurement Results}

To arrive at an understanding of ELF electrode design factors, analytical calculations, computational electromagnetics software simulation, and field measurements were completed on the various test scenarios.

An ELF system has at least three sources of noise: 1) internal noise that the system generates itself, 2) external man-made noise, and 3) external natural noise coupling to the electrodes from the Earth [13]. The wires connecting the receiving rods to the receiver can also pick up interference. When connected to earth, the ELF system detects voltage at that location created by stray currents flowing in the Earth created by chemical reactions, man-made sources, or thunderstorm activity. Since all three sources combine to form a noise floor, noise must be evaluated at the site at the time of installation.

Because interference from man-made frequency sources is inevitable, frequencies were chosen to be below or in between $60-\mathrm{Hz}$ harmonics - a common source of interference at many sites in the U.S. Frequencies were selected that are not first or second harmonics of each other, so measurements of multiple frequencies could be recorded almost simultaneously without producing interference of their own.

\section{Test no. 1 - Electrode impedance based on number of rods}

The purpose of this test is to investigate how the TTE system's impedance varies by ground rod number per

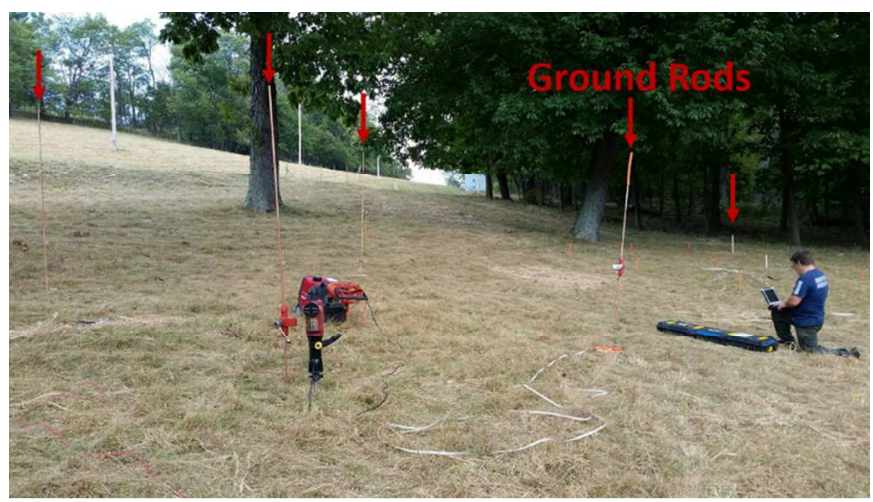

Fig. 10. Testing at one end of an earth electrode.

electrode. The ratio of the system's voltage divided by the current represents the magnitude of the system's impedance when connected to earth. It is important to note that the measured impedance using this method is the entire measurement system's impedance including both wire impedance and grounding impedance between rods. If the system were moved to another location, results may be different.

For this test, ground rods were directly driven into the ground using a hammer drill with a pounding bit. Choosing to start with more than one or two rods per electrode limited the effects of a single point of grounding, which may have contained anomolies if the immediate ground had a lot of rocks or tree roots present but locations over $2.4 \mathrm{~m}$ away may not have such obstructions. The testing rod locations are shown in Fig. 10.

Frequencies selected for measurement were 20, 100, 330, 990, and $3030 \mathrm{~Hz}$. These chosen frequencies cover a range above ELF to determine if there is any change based on frequency and to what degree that change could be. Results from these measurements are shown in Fig. 11.

Using FEKO, a similar setup was simulated, also varying the number of ground rods per electrode. An ideal amplifier was connected to electrodes with the same parameters as mentioned before. A sigma of $0.01-\mathrm{S} / \mathrm{m}$ was assumed in this case. Results from the FEKO simulation are shown in Fig. 12.

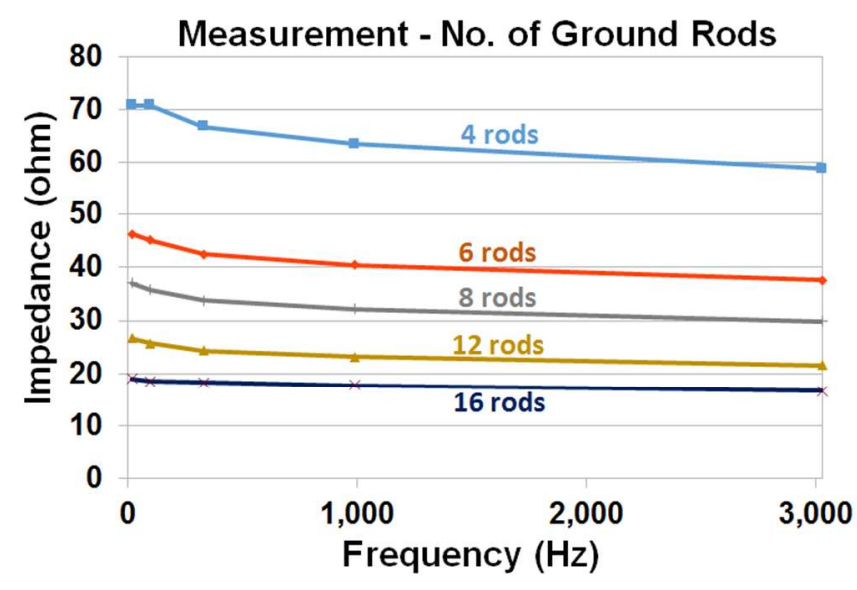

Fig. 11. Field measurements varying the number of rods per electrode. 


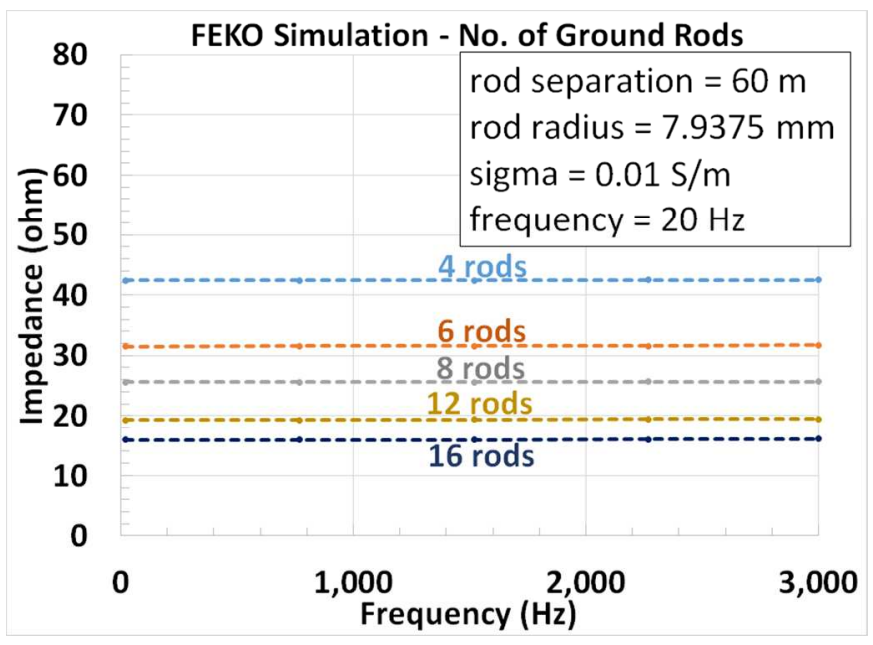

Fig. 12. FEKO simulation varying the number of rods per electrode.

Comparing Figs. 11 and 12, these is some agreement between measurements and simulation, respectively. The impedance is inveresely proportional to the number of rods. For measurement, there is a decrease in the magnitude of the impedance as frequency increases. For the simulation, there is a slight increase in the impedance with a rise in frequency. In FEKO, a very small inductance was found in the system which increased the impedance presented to the transmitter at higher frequencies.

Measurement is less simple. The rods themselves and their connections to the earth will contribute to the overall impedance not present in the simulation. Isolating these variables was out of the scope for this study, so the results of all measurements in determining the impedance are the resulting magnitude of $Z(|Z|)$.

Test no. 2 - Impedance based on the depth of rods per electrode

For this test, the purpose was to change only the depth of ground rods per each electrode on the TTE transmit system and determine the change in current generated in the system. The rods used for this test were incrementally driven into the earth with measurements taken at each increment. Results from the measurements are shown in Fig. 13.

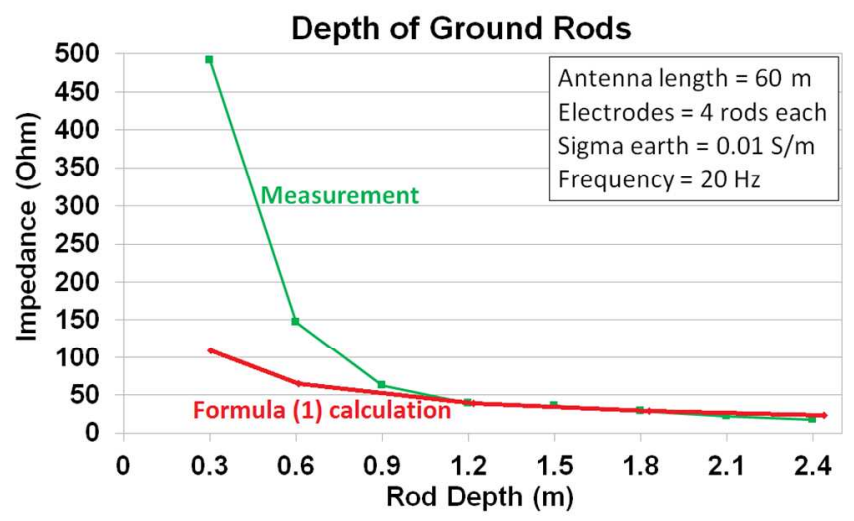

Fig. 13. Simulation-measurement of impedance based on rod depth, $20 \mathrm{~Hz}$.
In Fig. 13, the measurement starts out much higher in impedance before converging with the simulation at around $1.2 \mathrm{~m}$. Similar to test no. 1, varying the frequency from 20 to $3000 \mathrm{~Hz}$. did not show a large change in the values of the simulation or measured impedance; there was less than a 5\% change in value for frequencies up to $3000 \mathrm{~Hz}$ once rod depth exceeded $1.2 \mathrm{~m}$.

Test no. 3 -Impedance based on installation method

The standard way to install ground rods is by directly driving them into the ground, by using a sledgehammer or by using a hammer drill with a pounding bit. In most cases, a force is applied to the very top of the rod, driving it into earth. This is thought to have a positive effect on impedance, by compacting earth around the rod.

An alternate method of installing ground rods was also investigated, to see if this gave reduced contact resistance. In this method a hole was drilled into earth less than the diameter of a ground rod to nearly the desired rod depth. Next, a solution of water and $\mathrm{CuSO}_{4}$ was poured into the hole. This was repeated until the hole remained full to the surface of the earth for at least 15 minutes. Ground rods were then inserted into the hole forcing some solution out of the hole and onto the surface. The earth around the rods were still wet during testing and some solution was reapplied to each rod. These rods were installed $2.4 \mathrm{~m}$ away from rods directly driven into the ground for test no. 1. Results of three different measurements are shown in Fig. 14.

The first measurement was taken using just 4 rods per electrode of the rods directly driven into the ground for test no. 1. These were not the same rods used in test no. 1 but a different set of 4 from the remaining 16 directly driven into ground. When comparing the 4 rods to several other sets of 4 rods, a result of about $70 \mathrm{ohms}$ was found, agreeing with previous measurements.

Next, $2.4 \mathrm{~m}$ away, new holes were drilled and the rods were installed with $\mathrm{CuSO}_{4}$. It was thought since the two sets of rods were relatively close that the ground impedance should be close. However, the rods with the $\mathrm{CuSO}_{4}$ measured about half the impedance as the other rods. As a final

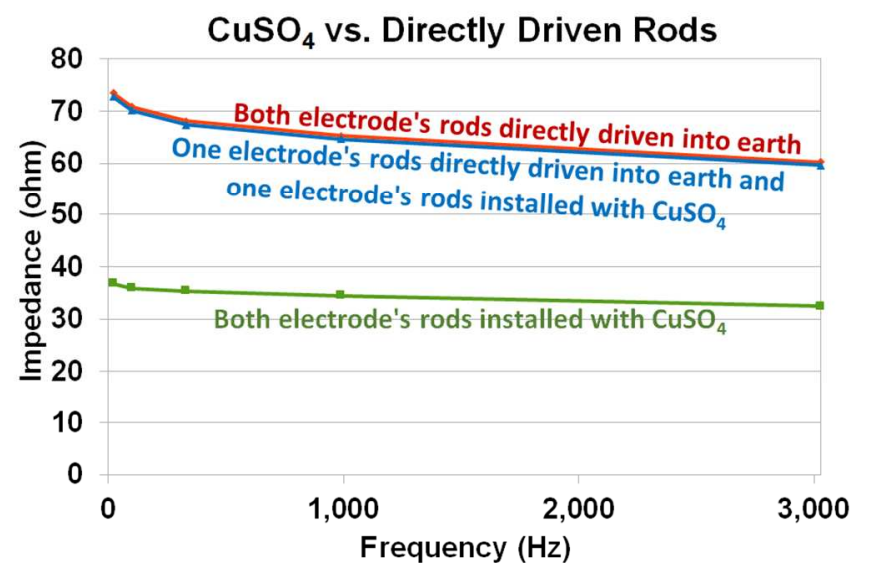

Fig. 14. Measurement of impedance based on rod installation 


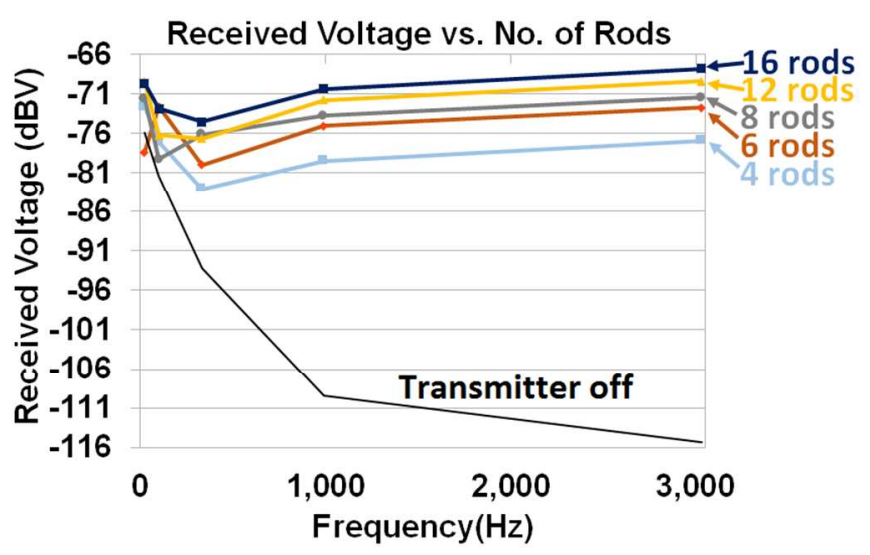

Fig. 15. Results for received signal varying the number of rods (test no. 1).

measurement, one electrode was connected to each of the two types of rods. This result measured almost the same impedance if both electrodes were directly driven although one was not. This indicates that the contact resistance of both electrodes is the dominant factor in the contact resistance at this site, and the use of $\mathrm{CuSO}_{4}$ solution can significantly reduce that impedance.

In order to determine if the results found during testing play a significant role in determining whether signal will propagate through earth, receive electrodes were monitored $365 \mathrm{~m}$ away from the transmit electrodes for all 3 tests.

As shown in Fig. 15, received signal increased several $\mathrm{dBV}$ with each incremental increase in the number of rods for most frequencies. For the lower frequencies $(20$ and $100 \mathrm{~Hz})$, the results were less stable possibly due to the high noise floor detected at those frequencies. The noise level was the measured voltage when the system was not transmitting.

Received voltage for test numbers 2 and 3 were taken and the same relationship was observed. As the impedance decreased the received signal increased. The received voltage increased when the depth of the rods increased. For example, the received voltage during test no. 2 was $-80.5 \mathrm{dBV}$ for $1.2-$ $\mathrm{m}$ rods and increased to $-71.2 \mathrm{dBV}$ for $2.4-\mathrm{m}$ rods for a frequency of $330 \mathrm{~Hz}$.

The same relationship was observes for test no. 3. As the impedance decreased, increased signal was observed. When $\mathrm{CuSO}_{4}$ was used the receive signal increased. For example, the received voltage was $-89.0 \mathrm{dBV}$ for rods installed without $\mathrm{CuSO}_{4}$ and increased to $-80.8 \mathrm{dBV}$ for rods with $\mathrm{CuSO}_{4}$ for $330 \mathrm{~Hz}$.

These results are thought to be due to decreased impedance at the transmit end $365 \mathrm{~m}$ away that allowed for a higher current to be injected into the earth. The noise level is voltage received while the transmit system is off. As expected, the measured impedance varies with location. The measured impedance at the receive side was about 14 ohms. This was significantly less than anything measured on the transmit side under nearly similar conditions.

\section{CONCLUSION}

In a TTE system, the earth's conductivity will play a role in the signal transmitted, but this factor is out of the control of the user in most cases, unless the user is able to move to another location and try transmitting again.

In some situations underground, the amount of voltage available is limited due to permissibility concerns. Since the voltage is limited, the only parameter that may be changed is impedance. In this work it was demonstrated that the overall impedance of the electrodes can be reduced by:

1. Using multiple ground rods at each electrode,

2. Increasing the depth of each ground rod, and

3. Using copper (II) sulfate solution

Figure 11, 13, and 14 show a progressive reduction in the measured impedance as these measures were taken. Reducing the electrode impedance increases the current injected at a given voltage, which in turn may allow for longer communication distances. Figure 15 shows that by increasing the current injected into the ground, the received voltage should increase. The measurements presented in the paper can serve as a reference to help understand some considerations for TTE system electrodes.

\section{DISCLAIMER}

Mention of a company name or product does not constitute an endorsement by the National Institute for Occupational Safety and Health. The findings and conclusions in this report are those of the authors and do not necessarily represent the views of the National Institute for Occupational Safety and Health. This article is not subject to US copyright law.

\section{ACKNOWLEDGEMENT}

The authors wish to thank Dr. Joseph A. Waynert for his contribution to the simulation and modeling of these experiments.

\section{REFERENCES}

[1] MINER Act 2006. Available at: http://arlweb.msha.gov/MinerAct/MinerActSingleSource.asp

[2] N. Damiano, G. Homce, R. Jacksha, "A Review of Underground Coal Mine Emergency Communications and Tracking System Installations," Coal Age magazine, pp. 34-35, November 2014. Available at: http://coal.epubxp.com/i/421812/64

[3] Mine Safety and Health Administration, 30 CFR Parts 7 and 75, "Refuge Alternatives for Underground Coal Mines; Final Rule," 2008 http://arlweb.msha.gov/MinerAct/MinerActSingleSource.asp

[4] E-Spectrum Technologies. "Ultra Low Frequency Through-The-Earth Communication Technology," Contract Final Report. Pittsburgh (PA): Broad Agency Announcement. Available from NIOSH, Pittsburgh, PA, Contract \# 200-2008-26818, 2009.

[5] MINER Act Compliant Communication \& Tracking Systems and Peripherals, page 7. Available at: http://arlweb.msha.gov/techsupp/PEDLocating/CommoandTrackingMI NERActCompliant.pdf Mine Safety and Health Administration, 2016

[6] L.Yan, C. Sunderman, "Electric Field of Grounded Horizontal Line Transmitter for Through-the-Earth Communication," presented at the 31st International Review of Progress in Applied Computational Electromagnetics (ACES 2015), Williamsburg, VA, 2015 
[7] J. Gomez, "Design and Calculation of an Earth Electrode," European Organization for Nuclear Research (CERN), CERN-ST-2000-053, 3rd ST Workshop, Chamonix, France, January 25-28, 2000.

[8] F.M. Tesche, M. Ianoz, T. Karlsson, EMC Analysis Methods and Computational Models, J. Wiley \& Sons, New York, 1996.

[9] R.L. King, H.W. Hill, Jr., R.R. Bafanna, and W.L. Cooley. "Guide for the Construction of Driven-Rod Ground Belts," U.S. Bureau of Mines, Information Circular 8767, 1978.

[10] V. Bataller, A. Muñoz, P. Molina, A. Mediano, J.A. Cuchí and J.L. Villarroel, "Improving Medium Access in Through-The-Earth VLF-LF Communications," Journal of Communications, vol. 4, no. 4, pp. 284294, 2009.

[11] L. Grcev, M. Popov, "On High-Frequency Circuit Equivalents of a Vertical Ground Rod," IEEE Transactions on Power Delivery, Vol. 20, No. 2, April 2005.

[12] Electrical Contractors' Association (2008) Guide to the IET Wiring Regulations: 17th Edition IET Wiring Regulations (BS 7671:2008), D. Locke, John Wiley \& Sons, Ltd, Chichester, UK, Appendix 12 - Earth Electrodes and Earth Electrode Testing.

[13] C. Bianchi, A. Meloni, "Natural and man-made terrestrial electromagnetic noise: an outlook," Annals of Geophysics, vol. 50, no. 3, June 2007. 